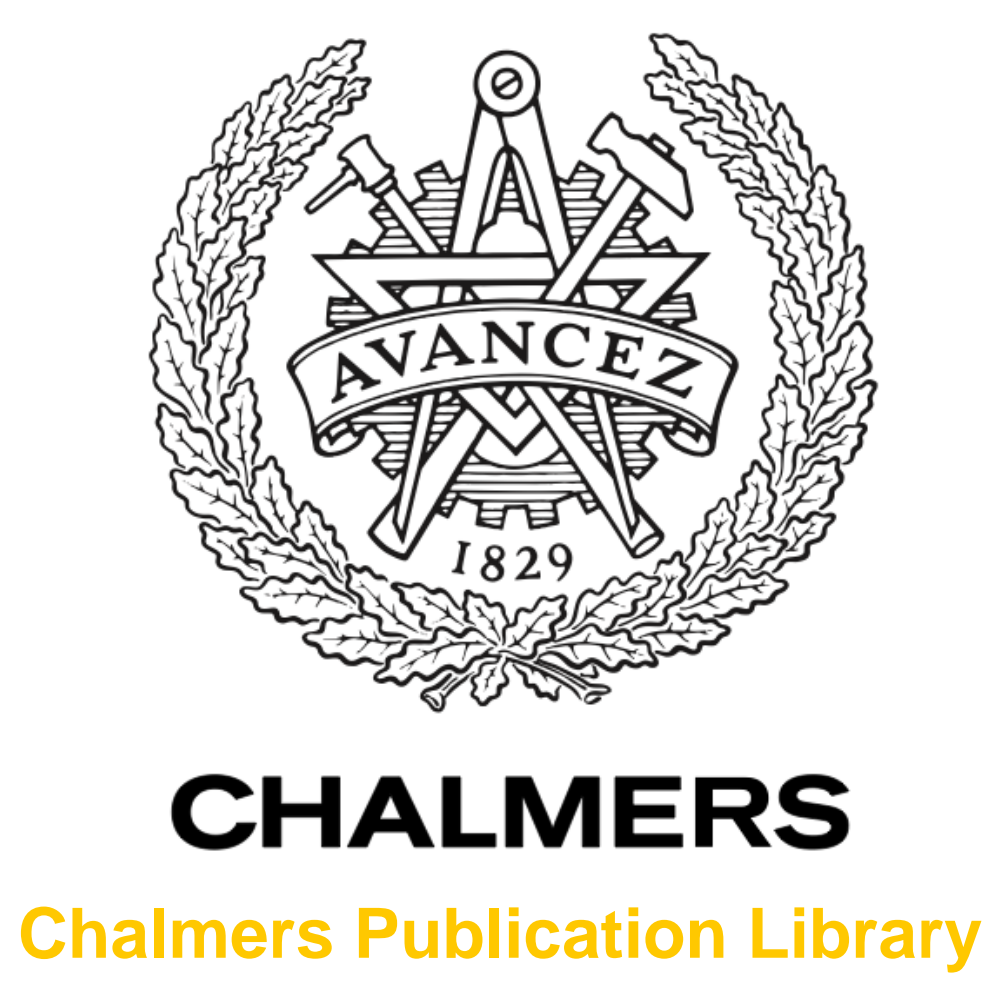

\title{
Wide-Band Slot Antenna Arrays With Single-Layer Corporate-Feed Network in Ridge Gap Waveguide Technology
}

This document has been downloaded from Chalmers Publication Library $(\mathrm{CPL})$. It is the author's version of a work that was accepted for publication in:

IEEE Transactions on Antennas and Propagation (ISSN: 0018-926X)

Citation for the published paper:

Zaman, A. ; Kildal, P. (2014) "Wide-Band Slot Antenna Arrays With Single-Layer

Corporate-Feed Network in Ridge Gap Waveguide Technology". IEEE Transactions on

Antennas and Propagation, vol. 62(6), pp. 2992-3001.

http://dx.doi.org/10.1109/tap.2014.2309970

Downloaded from: http://publications.lib.chalmers.se/publication/200389

Notice: Changes introduced as a result of publishing processes such as copy-editing and formatting may not be reflected in this document. For a definitive version of this work, please refer to the published source. Please note that access to the published version might require a subscription. 


\title{
Wide-band Slot Antenna Arrays with Single- layer Corporate-Feed Network in Ridge Gap Waveguide Technology
}

\author{
Ashraf Uz Zaman and Per-Simon Kildal, Fellow, IEEE
}

\begin{abstract}
Single layer, wideband and low-loss corporate-feed networks for slot antenna arrays are described. The antenna is built using ridge gap waveguide technology, formed between two parallel metal plates without the requirements of electrical contact between these plates. The corporate-feed network is realized by a texture of pins and a guiding ridge in the bottom plate, and the radiating slots are placed in the smooth top plate. The paper describes two test antennas: a $4 \times 1$ linear slot array and a $2 \times 2$ planar slot array. Both have been fabricated and tested at $\mathrm{Ku}$ - band. The linear array shows more than $20 \%$ bandwidth and the $2 \times 2$ array shows a bandwidth of $21 \%$ for $10 \mathrm{~dB}$ return loss. There are good agreements between measured and simulated patterns for both antennas. Measured gain for the planar array is found to be at least $12.2 \mathrm{dBi}$ over 12-15GHz band.
\end{abstract}

Index Terms - corporate-feed, waveguide slot array antenna, wideband, ridge gap waveguide, PMC, PEC.

\section{INTRODUCTION}

$\mathrm{P}$ LANAR-ARRAY ANTENNAS are suitable for a lot of applications requiring high to moderate antenna gain. Microstrip antenna arrays and waveguide slot arrays are the two main planar antenna technologies, which have been used extensively over a wide range of frequencies. Microstrip arrays are compact, easy to manufacture, cost-effective and easy to integrate with active electronics. However, the microstrip feed networks suffer from high ohmic and dielectric losses at high frequency [1-2]. Spurious radiations and leakage in the form of surface waves are always major concerns in microstrip antennas and are difficult to handle [3]. All these lead to substantial reduction in gain and antenna efficiency. Substrate integrated waveguide (SIW) or post-wall based planar array antennas have been proposed to realize low cost solutions [4-5]. This technology enables integration of active circuits together with the antennas. The losses in SIW are better than microstrip and coplanar structures. Still, losses may be of concern, especially for high gain (above 30dBi)

Manuscript received May, 2013. This work has been supported in part by the Swedish Research Council VR, and by The Swedish Governmental Agency for Innovation Systems (VINNOVA) within the VINN Excellence Center Chase.

A.Uz Zaman and P.-S. Kildal are with the Department of Signals and Systems, Chalmers University of Technology, SE-412 96 Göteborg, Sweden.

phone: +46 317721794 ; fax: +46 3177217 48; e-mail: (zaman@) chalmers.se; per-simon.kildal@chalmers.se). antennas, due to the presence of dielectric material [6-7]. On the other hand, waveguide slot arrays have low losses. They suffer neither from dielectric nor radiation loss. So, waveguide slot arrays are considered for many applications requiring high gain and high efficiency. However, wideband waveguide slot arrays require corporate-feed networks that become very complex and bulky. At high frequencies, such networks require accurate and high precision (and thereby expensive) manufacturing so as to achieve good electrical contacts between the slotted metal plate and the bottom feed structure [8]. The present paper will describe a compact ridge gap waveguide corporate-feed network without the need of metal contact between these two plates, thereby having simple mechanical assembly and potentially lower manufacturing cost.

Apart from the manufacturing costs and assembly complications, some other limitations of waveguide slot arrays have been reported in literature. Series-fed single layer waveguide slot arrays are simple but have narrow bandwidth due to the long line effect [9] (i.e. different delays to each element). In a single layer structure, it is normally not possible to feed each radiating element in parallel (full corporate-feed) because of the space limitations associated with keeping the element spacing smaller than one wavelength $\left(\lambda_{\mathrm{o}}\right)$ to avoid grating lobe [10-11]. Therefore, there is needed a complex multilayer feed network. Such a double-layer corporate-feed network in rectangular waveguide technology is described in [12]. It was realized with diffusion bonding of laminated thin metal plates and the antenna worked over $11 \%$ relative bandwidth. The present paper describes a much simpler and single-layer corporate-feed network.

Based on the above discussion, existing corporate-feed network technologies have limitations with respect to bandwidth and mechanical simplicity, giving an opportunity for the proposed gap waveguide technology. The gap waveguide technology introduced in [13] uses the basic cutoff of a PEC-PMC parallel-plate waveguide configuration to control desired electromagnetic propagation between the two parallel plates. In the realized gap waveguide, the PEC-PMC cut-off becomes a stopband, and this stopband can be achieved by a periodic structure, such as metal pins or mushrooms in the textured surfaces [14]. However, the textured surface must also incorporate guiding structures in 
the form of ridges, grooves or strips. As a result of the stopband, the electromagnetic waves can propagate along these ridges, grooves or strips without leaking away in other directions. These guiding structures thereby define three different gap waveguides or transmission lines, referred to as ridge, gap and microstrip gap waveguides [15]. Thus, gap waveguide technology offers mechanically flexible guiding structures where good electrical contact between the building blocks is not an issue at all. Consequently, high precision metal machining required for assembling and manufacturing waveguide slot arrays can be avoided and cost of production can be minimized. The first experimental validations of the ridge gap waveguide and the suspended microstrip gap waveguide were published in [16-18] respectively. In the present paper, we will use ridge gap waveguide to design a linear slot array and a planar slot array. The ridge gap waveguide structure used in the linear array design is shown in fig.1(a). The planar array antenna, on the other hand, uses periodic pin structure with a bit different dimension. The stopband and the dispersion diagram for both the pin structures are discussed in Section-II.
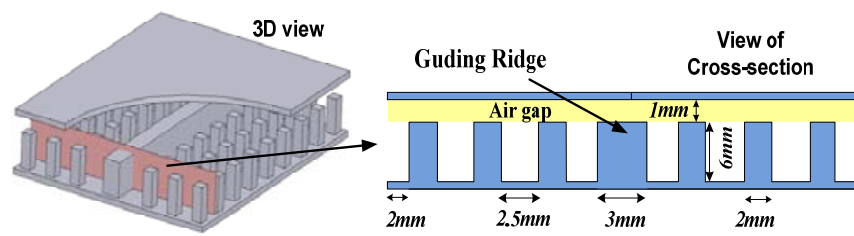

Fig.1 (a) Detailed dimensions of the periodic metal pin and ridge gap waveguide geometry used in this paper.

Till now, there have been no complete papers on gap waveguide antennas, except for some conference papers describing horn antenna [19], initial works in single hard-wall waveguide slot array in [20], and single slot design in ridge gap waveguide [21]. We should also mention the multi-layer phased array antenna and dual mode horn array based on related technology presented in [22-23]. Recently, series fed groove gap waveguide slot array having inclined slots in narrow wall has also been reported [24]. But this slot array was narrow band $(5 \% \mathrm{BW})$. In the present paper, we document wideband $4 \times 1$ element linear slot array and a $2 \times 2$ element planar slot array designed at $\mathrm{Ku}$ band based on ridge gap waveguide technology. Both these antennas are designed for a fixed broadside beam and a $20 \%$ relative bandwidth. In a wideband antenna, the reflection coefficient $S_{11}$ of each component constituting the antenna must be very good to avoid interference maxima of the total $S_{11}$ of the complete antenna over all the frequencies within the band of interest. The wideband single slot element and a wideband single Tjunction based on ridge gapwaveguide were first presented in [21]. Similar slot element and T-junction have been used in the linear array in the present paper. This is explained in Section-IV. However, the present $2 \times 2$ planar slot antenna has more compact feed-network geometry, and the shape of the slot and the feed $\mathrm{T}$-section is different. The $2 \times 2$ planar antenna design is described in Section- $\mathrm{V}$. The linear array is excited with a conventional coaxial SMA connector with an extended center conductor, and the $2 \times 2$ planar array is excited with a transition from ridge gap to rectangular waveguide.
Measured results for both these antennas are presented in Section-VI and are carefully compared with the simulated results.

The design of the two slot arrays in the paper has been done entirely by numerical simulations using a cut-and-try approach based on intelligent guessing from previous experience. The ridge gap waveguide modes look similar to the modes along inverted microstrip lines, so the topologies of different ridge gap waveguide circuits will look similar to those of microstrip circuits [25], which is of help in the design process. The topology of ridge gap waveguides is too complex for analytic treatment, although some analytic works have been done [2627].

\section{DESIGNING THE STOPBAND}

As mentioned in [16], the main performance of the gap waveguide is determined by its ability to create parallel-plate stopband for wave propagation in undesired directions. This ability is determined by the quasi-periodic pin structure and the height of the air gap. The size of the stopband is directly linked to the operational bandwidth of the power dividers and feeding network, and hence to the whole gap waveguide antenna. The stopband study consists of parametric sweeps of all parameters associated with the periodic structure to be used ( $a, p, d$ and air $_{\text {gap }}$ in this paper), and it is based on Eigen mode analysis of the single unit cell by enforcing periodic boundary conditions on the sides of the structure. The details of such types of studies can be found in [14]

For both the slot arrays in the present paper we use a textured surface made of square pins, designed to have the stopband in Ku-band, covering 12-15 GHz. The dispersion diagrams for the parallel-plate geometry with metal pins that are used in the linear array and the $2 \times 2$ planar array are shown in fig.1(b) and fig.1(c), respectively. The pin dimensions for the two cases are also shown in the figures.

As shown in the above two figures, a large stop-band is created by the pin surface after $10 \mathrm{GHz}$ where all the parallelplate modes are in cutoff. Once the dimensions of the periodic pin structure are obtained, the ridge can be incorporated within the periodic pin structure. The ridge height is kept same as the pin height everywhere in the gap waveguide structures. It is to be noted that- while designing the bends of the T-junctions, a few pins have to be removed or relocated locally. As long as the modification is done locally over one or two pins, this does not have severe consequence on the designed stop-band and on the performance of the gap waveguide structures, provided the relocations are done locally over one or two pins.

Apart from the stopband design, the number of pin rows around the guiding ridge is also very important for gap waveguide antennas as it will dictate the element spacing of the antenna and grating lobe issue. So, we have done a simple two-port analysis of the basic ridge gap waveguide structure with varying number of pin rows. We have simulated a $150 \mathrm{~mm}(\sim 7.5 \lambda$ at $15 \mathrm{GHz})$ ridge gap waveguide with three, two and single rows of pins, respectively. The $S_{21}$ is almost identical for the three and two rows of pins. For single row of 
pins, the $\mathrm{S}_{21}$ is degraded by $0.1 \mathrm{~dB}$ over the whole Ku-band. This is shown in fig.1(d). Thus, two pin rows are preferable for such structures considering losses and isolation an issue. For designing the antennas without grating-lobes, we have relaxed this requirement and used one row of pin at some locations to have the adjacent elements in less than $1 \lambda$ spacing. We have done a tradeoff and expect some leakage to neighboring elements but this leaked energy will be as low as - $20 \mathrm{~dB}$ after one row of pins [13] and is acceptable for many antenna designs.

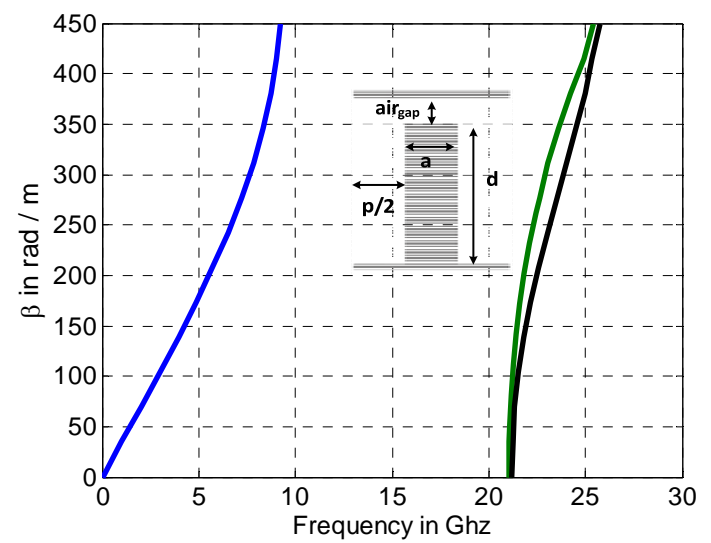

Fig.1 (b) Dispersion diagram of the unit cell of the periodic pins used in the linear array design, $\mathrm{a}=2 \mathrm{~mm}, \mathrm{p} / 2=1.25 \mathrm{~mm}, \mathrm{~d}=6 \mathrm{~mm}$ and air $_{\text {gap }}=1 \mathrm{~mm}$.

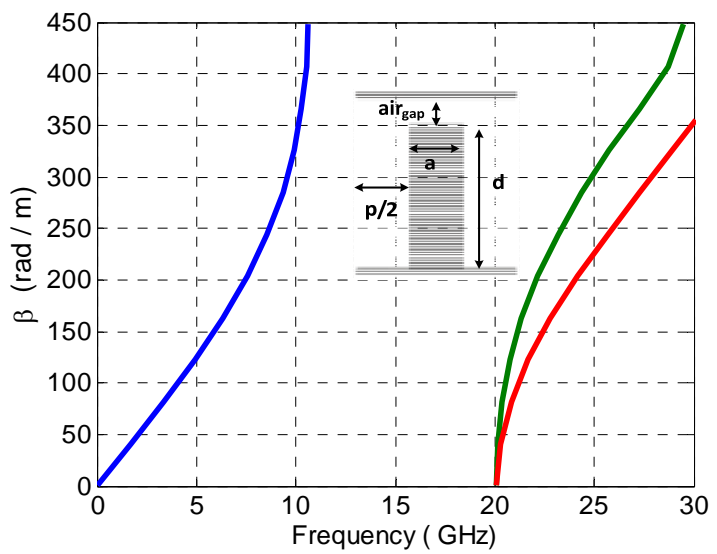

Fig.1 (c) Dispersion diagram of the unit cell of the periodic pins used in the planar array design, $\mathrm{a}=1.75 \mathrm{~mm}, \mathrm{p} / 2=0.85 \mathrm{~mm}, \mathrm{~d}=6.15 \mathrm{~mm}$ and air $_{\text {gap }}=1$ $\mathrm{mm}$.

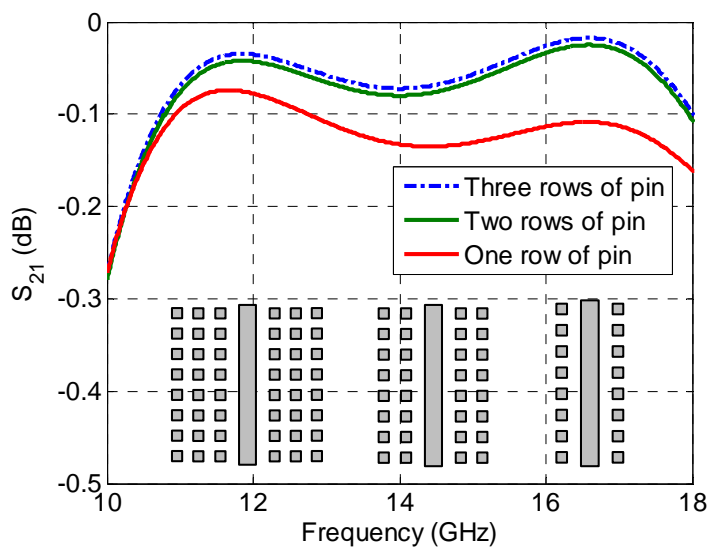

Fig. 1(d) Simulated $\mathrm{S}_{21}$ for different rows of pins around the guiding ridge.

\section{DeSign Rules For THE SINGLE ELEMENT, POWER DIVIDER AND TRANSITIONS}

We have designed both antennas based on full wave simulations. First, we have determined the geometry of the half-wavelength resonant slot element fed by a simple ridge gap waveguide. Then, we have tried to improve the bandwidth by adding a $\mathrm{T}$-section to the feeding ridge structure under the slot element shown in fig.2(a). The largest bandwidth is obtained when the first resonance from the slot itself and the second resonance from the feeding T-section appeared close to each other. These two resonance deeps are clearly seen in the simulated $S_{11}$ plots in fig. 2(b).

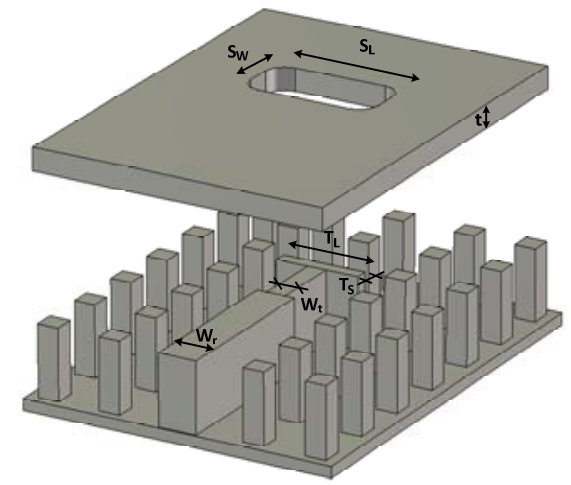

Fig.2 (a) Drawing of the slot element with T-section; $\mathrm{S}_{\mathrm{L}}=11.825 \mathrm{~mm}, \mathrm{~S}_{\mathrm{W}}=$ $5.8 \mathrm{~mm}, \mathrm{~T}_{\mathrm{L}}=8.15 \mathrm{~mm}, \mathrm{~T}_{\mathrm{S}}=1 \mathrm{~mm}, \mathrm{~W}_{\mathrm{r}}=3 \mathrm{~mm}, \mathrm{~W}_{\mathrm{t}}=2 \mathrm{~mm}$ and $\mathrm{t}=2 \mathrm{~mm}$. The air gap between pins and the top plate is $1 \mathrm{~mm}$, even though it is shown bigger in the drawing.

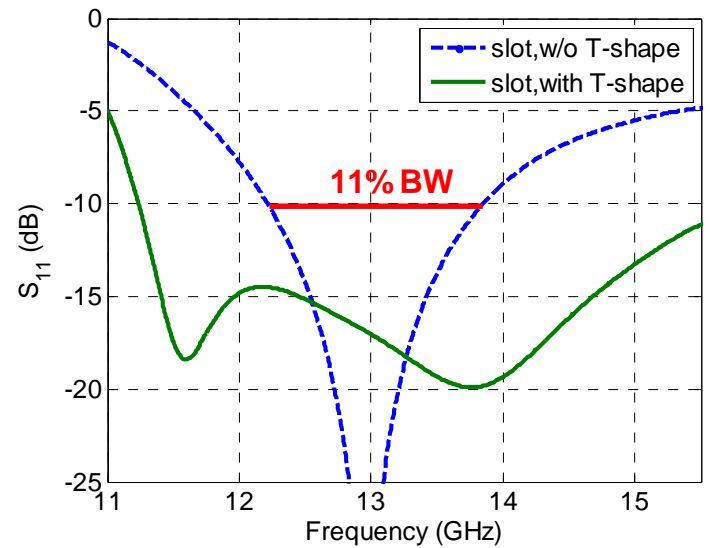

Fig.2 (b) Simulated $\mathrm{S}_{11}$ for the slot element with and without the T-shape in the feeding ridge section.

Parametric sweeps have been done for several design parameters such as $T_{L}, T_{s}$ and $W_{t}$ and $S_{w} / S_{L}$ (shown in fig. 2) to achieve reasonable bandwidth of the single slot element. During the parameter sweeps, we have found that the parameters $S_{w} / S_{L}$ and $T_{L}$ have larger impact on the impedance bandwidth. On the other hand the parameters such as $\mathrm{T}_{\mathrm{S}}$ and $\mathrm{W}_{\mathrm{t}}$ have relatively smaller effect on the reflection coefficient of the single slot element. The influence in simulated $S_{11}$ due to variations in $S_{w} / S_{L}$ and $T_{L}$ are shown in fig. 2(c) and 2(d). 


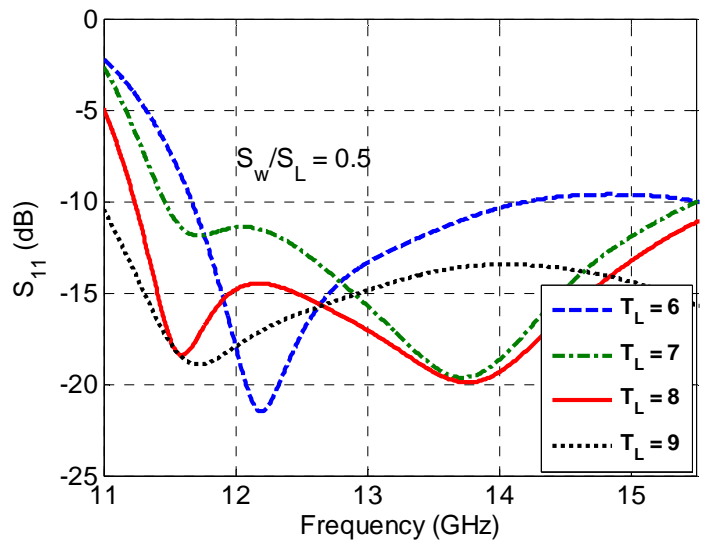

Fig.2 (c) Variation in parameter $T_{L}$ of the T-shape section, $S_{w} / S_{L}$ is kept 0.5 .

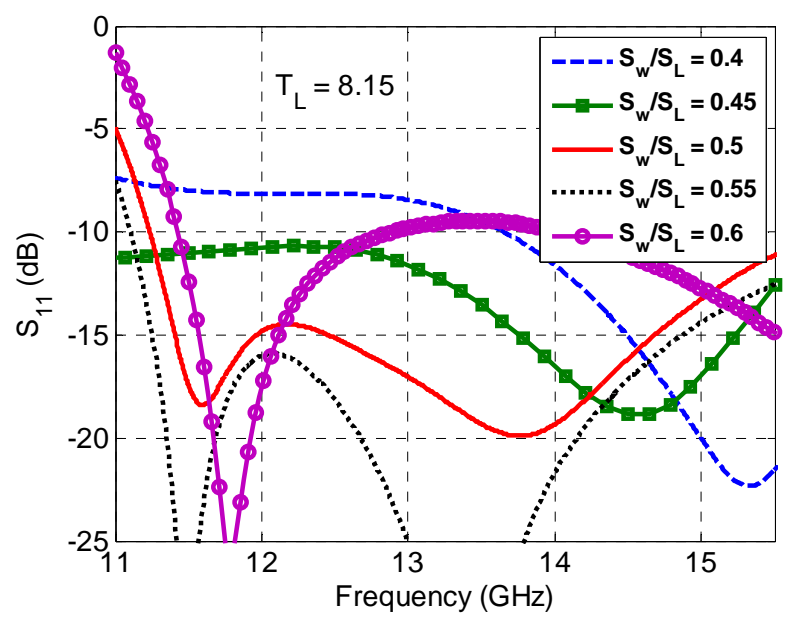

Fig.2 (d) Variation in parameter $\mathrm{S}_{\mathrm{w}} / \mathrm{S}_{\mathrm{L}}$ of the slot element, $\mathrm{T}_{\mathrm{L}}$ is kept $8.15 \mathrm{~mm}$.

The power dividers are based on well-known two-way power division technique (T-junctions) used in microstrip technology. The power divider for the linear array case is based on impedance matching of the input line using a single quarter-wavelength section which gives $30 \%$ bandwidth. The power divider used in the $2 \times 2$ planar array case is based on a gradual tapering from low-impedance to high impedance. No $\lambda / 4$ transformers were used and thereby it could be made more compact in size, and the bandwidth obtained was still $22 \%$ which is enough for our demonstrator.

The stepped transition (fig.5a) from ridge gap waveguide to groove gap waveguide used in the linear array case is based on using different sections of Chebyshev transformers for the impedance matching. This technique is well described in [28]. The $2 \times 2$ planar array has a $90^{\circ}$ transition from ridge gap waveguide to rectangular waveguide (fig. 9). The starting point of this transition design is the well-known microstrip to waveguide transition in [29]. As the mode in ridge gap waveguide is also a quasi-TEM mode, ridge gap waveguide to rectangular waveguide transition can be designed in a similar way as the microstrip transition. Later, we have optimized the ridge gap waveguide transition to work well within our frequency of interest.

\section{LINEAR ARRAY DESIGN}

Initial simulated results for the $\mathrm{Ku}$-band linear slot array were presented in [30]. The slot element used in that work was exited with a ridge having the width $\mathrm{W}_{\mathrm{r}}=3 \mathrm{~mm}$. That ridge had a prolonged T-shaped section that was added to achieve good impedance bandwidth. The results presented in [30] were done with slot elements having sharp rectangular corners. However, slots with sharp corners are difficult to manufacture and need very small diameter tool to mill the slot. To address this issue, the slot element was redesigned with rounded corners. The new slot element with rounded corners is shown in previous section. The simulated reflection coefficient for this new slot element is shown in fig. 3(a). Apparently, there is almost no effect of the rounded corners compared to sharp cormers if the dimension of the slot is retuned. The dimensions of the T-section are kept unchanged. The dimension of the slot element is chosen in such a way that the slot length to width ratio ' $S_{w} / S_{L}$ ' is kept smaller than 0.5 . This ratio is important for the suppression of the crosspolarization. The thickness ' $t$ ' of the top metal plate is chosen to be $2 \mathrm{~mm}$.

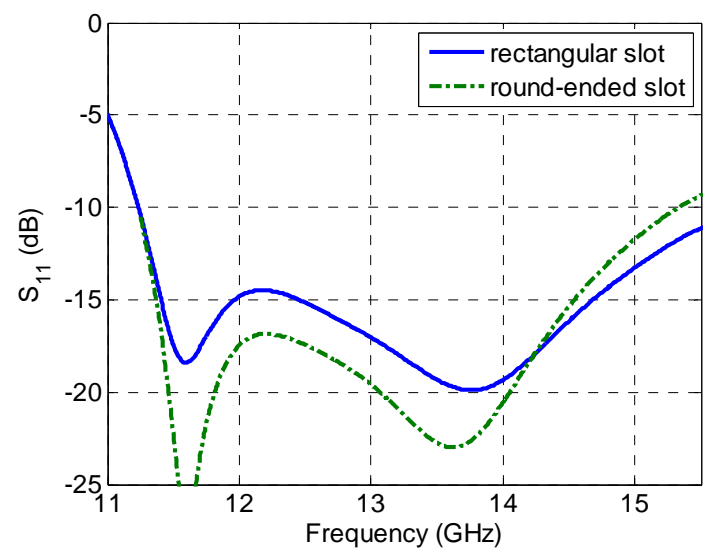

Fig.3 (a) Simulated $S_{11}$ for the rounded edge slot element.

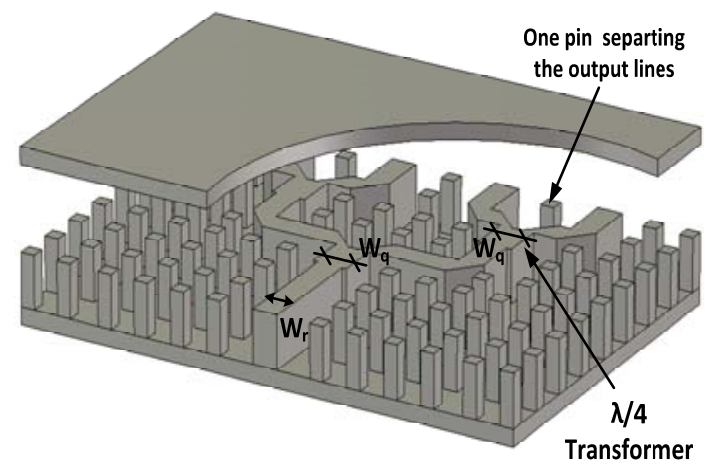

Fig.3 (b) 4-way power divider with the T-junctions; $\mathrm{W}_{\mathrm{r}}=3 \mathrm{~mm}, \mathrm{~W}_{\mathrm{q}}=4.2 \mathrm{~mm}$. The upper plate is shown lifted up and partly removed for clarity.

The 4-way power divider needed to build the feeding network is based on the T-junction presented in [21]. In the initial design, the two output lines of the T-junction were separated by two rows of pins. For the array antenna, we have a limitation in terms of spacing between the adjacent elements. With two rows of pins, it is not possible to have the separation 
between the adjacent elements smaller than $\lambda_{0}$. Therefore, we designed a more compact power divider with a 4-way power division. The compact 4-way power divider is shown in fig.3 (b) and the simulated performance for this power divider is shown in fig.3(c). The simulated S-parameter results demonstrate good performance. Over the frequency band 11$15 \mathrm{GHz}$, equal power distribution is achieved and the input reflection coefficient $S_{11}$ is lower than $-20 \mathrm{~dB}$.

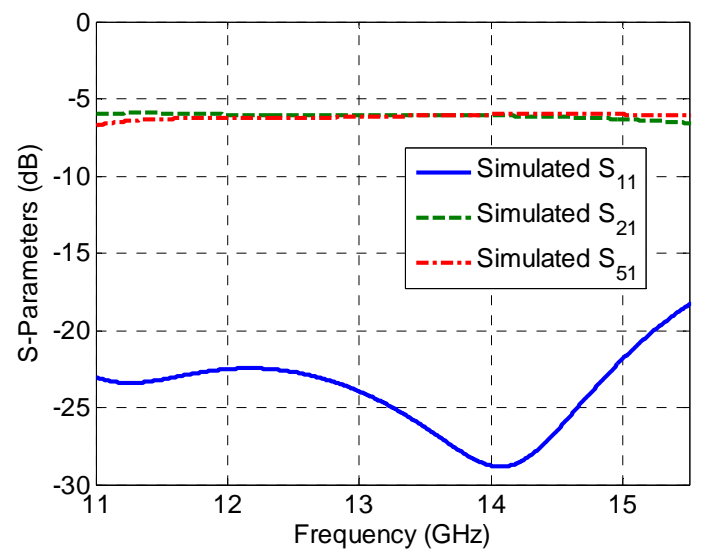

Fig.3 (c) Simulated results for the 4-way power divider.

The linear array has been designed for a fixed broadside beam. Therefore, the spacing between the elements was chosen to be $0.8 \lambda_{\mathrm{o}}$ to ensure no grating lobes. All the slot elements are excited with equal amplitude and phase, and the array was designed to operate from 12 to $14 \mathrm{GHz}$. The complete array antenna is shown in fig.4. Fig. 4 also shows a transition from ridge gap waveguide to groove gap waveguide.

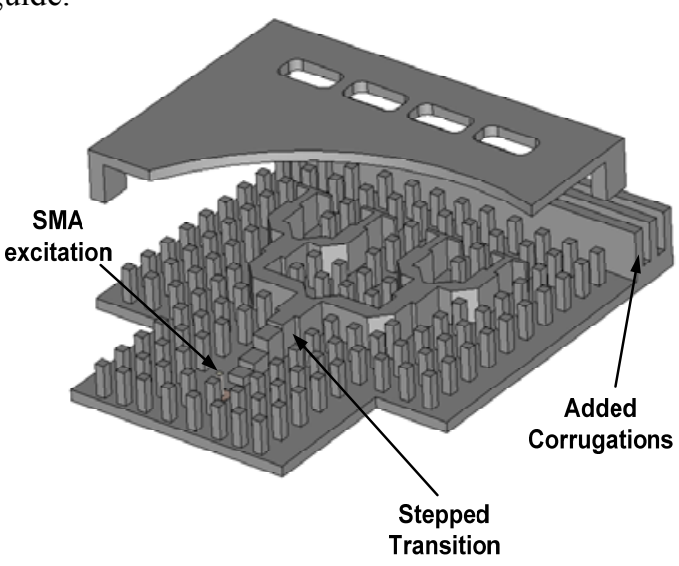

Fig.4 Complete linear array geometry. the upper plate is shown lifted and partly removed for clarity.

The propagating mode in a groove gap waveguide is very similar to the $\mathrm{TE}_{10}$ mode of rectangular waveguide [25]. Therefore, in the groove gap waveguide part the linear array antenna can be excited in an easy way by a coaxial SMA connector with an extended center conductor and a usual back short. The details of the ridge gap to groove gap transition are shown in fig.5 (a). Simulated results for this transition and the complete antenna are shown in fig.5 (b). The designed stepped transition is very wideband and the reflection coefficient $S_{11}$ of the transition is not the main contributing factor in $\mathrm{S}_{11}$ of the complete antenna. Instead, the $\mathrm{S}_{11}$ of the slot element and the 4-way power divider dominates and adds up in phase after $15 \mathrm{GHz}$. This causes the overall $\mathrm{S}_{11}$ of the antenna to rise above $-10 \mathrm{~dB}$ around $15 \mathrm{GHz}$. This $4 \times 1$ element linear array will have a directive symmetric radiation pattern in H-plane. The E-plane pattern will be wide, and this will cause significant back radiation because the slots are close to the edge. The level of the back radiation has been reduced by adding 2 corrugations with quarter wavelength depth at the lowest frequency of operation. The simulated radiation patterns for this linear array at $13 \mathrm{GHz}$ are shown in fig.6.

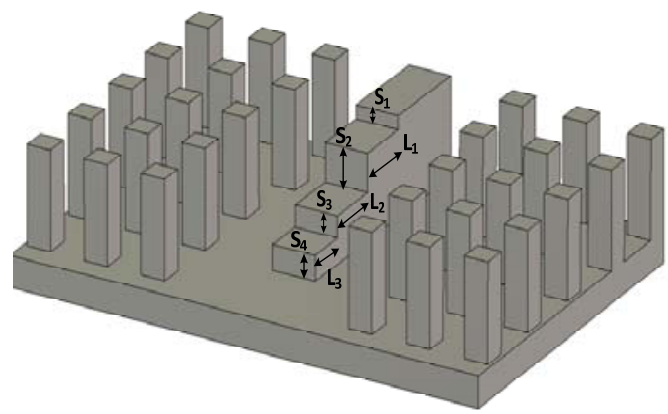

Fig.5 (a) Stepped transition from ridge gap waveguide to groove gap waveguide, $\mathrm{S}_{1}=0.85 \mathrm{~mm}, \mathrm{~S}_{2}=2.45 \mathrm{~mm}, \mathrm{~S}_{3}=1.35 \mathrm{~mm}, \mathrm{~S}_{4}=1.6 \mathrm{~mm}, \mathrm{~L}_{1}=4.6 \mathrm{~mm}$; $\mathrm{L}_{2}=4.5 \mathrm{~mm}, \mathrm{~L}_{3}=3.35 \mathrm{~mm}$ (top metal plate not shown).

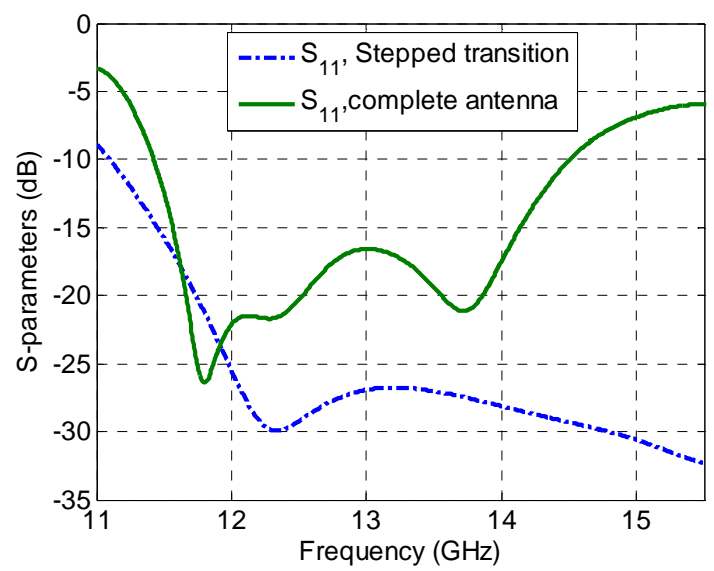

Fig.5 (b) Simulated $\mathrm{S}_{11}$ for the stepped transition from ridge gap waveguide to groove gap waveguide and the complete linear array antenna.

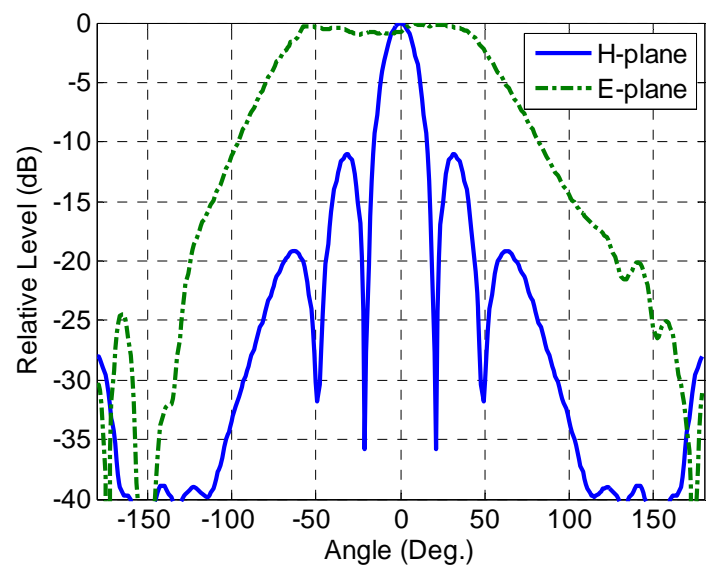

Fig.6 Simulated radiation patterns for the linear array at $13 \mathrm{GHz}$. 


\section{Planar $2 \times 2$ ARRAY DESIGN}

In a two-dimensional array, it is more difficult to design the corporate-feed network because the element spacing must be smaller than one wavelength in two orthogonal directions. For this reason, the feed network must be much more compact. Also, the slot elements must be redesigned. The slot element with the new dimensions is shown in fig.7(a) and the simulated reflection coefficient for this new slot element is shown in fig.7(b). The ' $S_{w} / S_{L}$ ' of the new slot element has been changed to 0.55 instead of 0.49 of the previous case. Also, the length of the T-section ' $T_{L}$ ' has been changed from $8.15 \mathrm{~mm}$ to $6.85 \mathrm{~mm}$ in this new design. The width of the exiting ridge has also been changed from $\mathrm{W}_{\mathrm{r}}=3 \mathrm{~mm}$ to $\mathrm{W}_{\mathrm{r}}=$ $2 \mathrm{~mm}$.

The compact 4-way power divider is designed without using a $\lambda / 4$ transformer section. Instead, the widths of the two divided ridge sections are gradually tapered to make the impedance match. This is shown in fig. 8 (a) and the simulation results for this 4-way power divider are shown in fig.8 (b). This new power divider is not as wideband as the one in Section III. Still, the power divider works well with $S_{11}$ below $-20 \mathrm{~dB}$ and equal power division from $12 \mathrm{GHz}$ to $15 \mathrm{GHz}$. After designing the new slot element and compact power divider, a simple $2 \times 2$ element planar array was designed to operate over the band $12-15 \mathrm{GHz}$. The $2 \times 2$ element array is excited in phase and with equal amplitude by a corporate feed network. The element spacing is chosen to be $17.5 \mathrm{~mm}$, which is about $0.875 \lambda$ at $15 \mathrm{GHz}$.

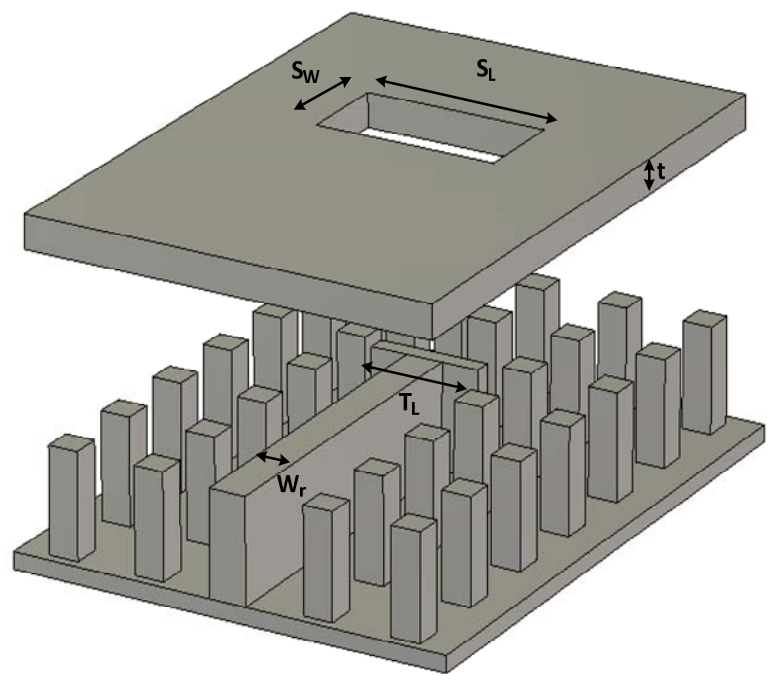

Fig.7 (a) Schematic of the modified slot element; $\mathrm{S}_{\mathrm{L}}=11.45 \mathrm{~mm}, \mathrm{~S}_{\mathrm{W}}=6.25$ $\mathrm{mm}, \mathrm{T}_{\mathrm{L}}=6.75 \mathrm{~mm}, \mathrm{~W}_{\mathrm{r}}=2 \mathrm{~mm}$ and $\mathrm{t}=2 \mathrm{~mm}$. The upper plate is shown lifted.

This antenna is excited with a standard $\mathrm{Ku}$-band rectangular waveguide from the bottom plane using a transition from rectangular waveguide to ridge gap waveguide. This transition is shown in fig.9 and the complete antenna is shown in fig. 10 (a). The simulated reflection coefficient for the antenna with the transition and the single transition performance is shown in fig. 10 (b). The simulated radiation pattern for this $2 \times 2$ element planar array at $15 \mathrm{GHz}$ is shown in fig. 11 .

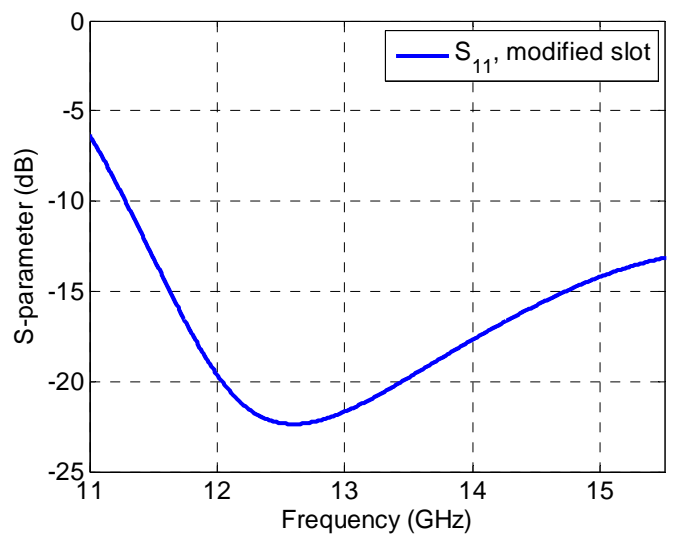

Fig.7 (b) Simulated reflection coefficient for the modified slot element.

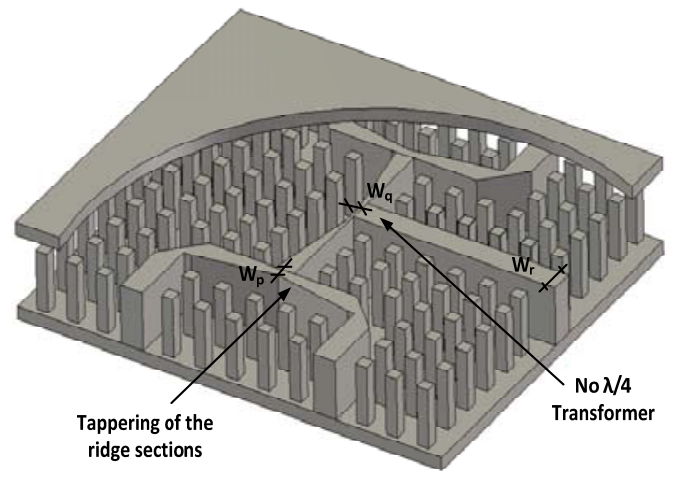

Fig.8 (a) Schematic of the modified T-junctions and 4-way power divider, $\mathrm{W}_{\mathrm{r}}$ $=2 \mathrm{~mm} \mathrm{~W}_{\mathrm{q}}=0.7 \mathrm{~mm}$ and $\mathrm{W}_{\mathrm{p}}=1.15 \mathrm{~mm}$.

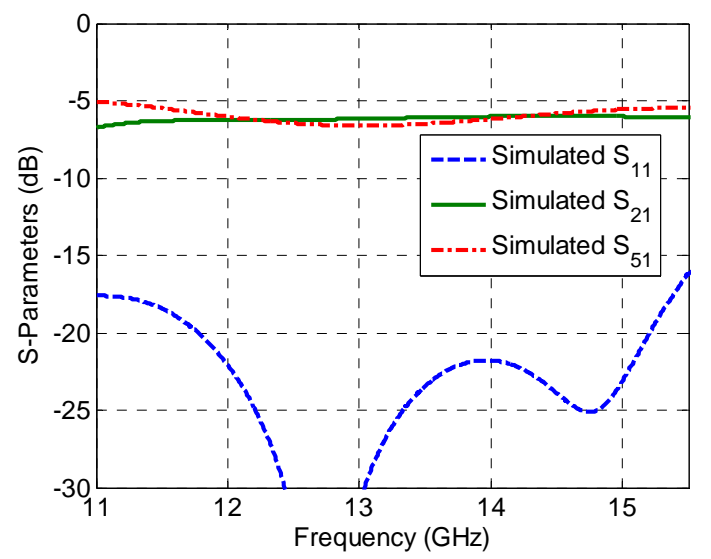

Fig.8 (b) Simulated S-parameters for the compact 4-way power divider.

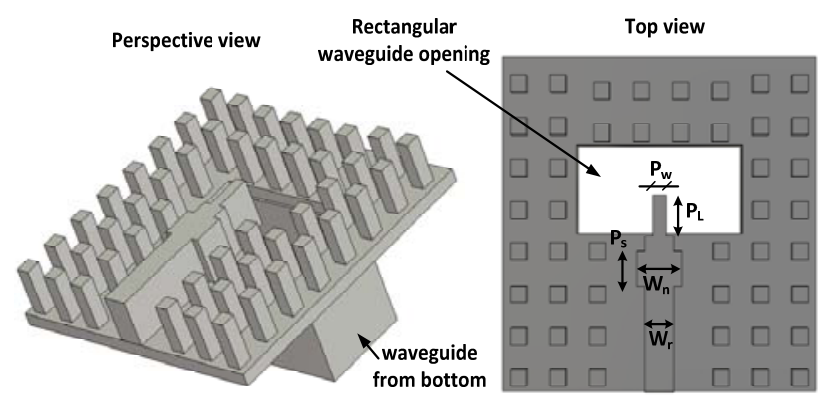

Fig.9 Rectangular waveguide to ridge gap waveguide transition, $\mathrm{P}_{\mathrm{L}}=3.65 \mathrm{~mm}$; $\mathrm{P}_{\mathrm{w}}=1.25 \mathrm{~mm} ; \mathrm{P}_{\mathrm{s}}=4.25 \mathrm{~mm} ; \mathrm{W}_{\mathrm{n}}=4 \mathrm{~mm} ; \mathrm{W}_{\mathrm{r}}=2 \mathrm{~mm}$. 


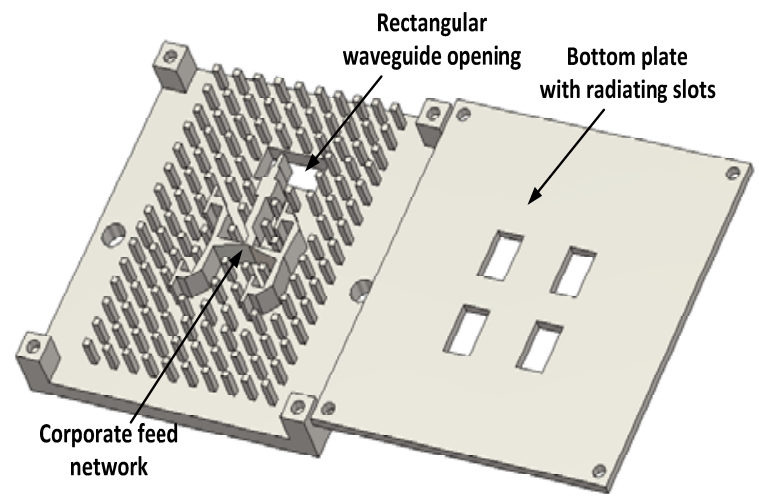

Fig. 10 (a) Complete $2 \times 2$ element array geometry; element spacing is $17.5 \mathrm{~mm}$.

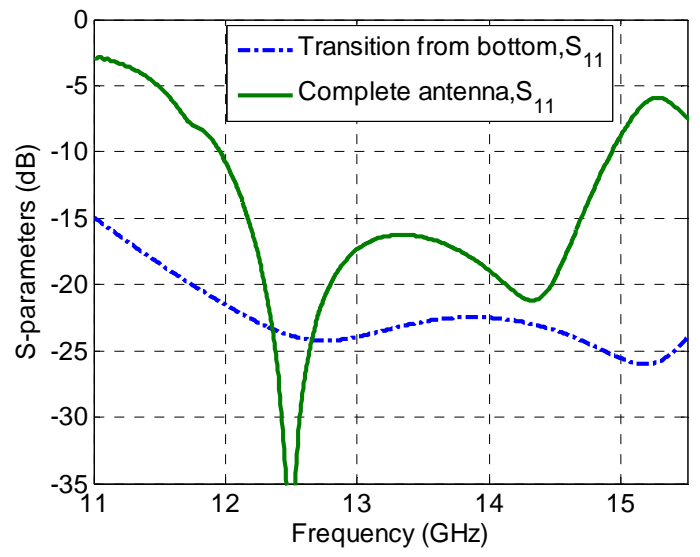

Fig. 10 (b) Simulated $\mathrm{S}_{11}$ for the bottom transition from ridge gap waveguide to rectangular waveguide and the complete planar antenna.

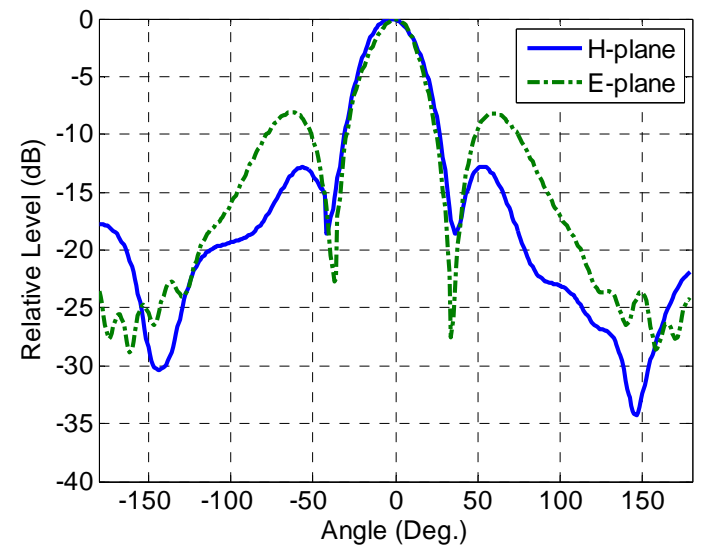

Fig.11 Simulated E-plane and H-plane radiation patterns for the planar array at $15 \mathrm{GHz}$.

\section{MEASUREMENT RESULTS}

\section{a) Reflection coefficients:}

Fig. 12 and fig.13 shows the manufactured linear array antenna and the planar antenna, respectively. Both these antennas are made in aluminum by metal milling technique with tolerance in the order of $25-30 \mu \mathrm{m}$. The input reflection coefficients, $S_{11}$ are shown in fig. 14 and fig. 15 for the $4 \times 1$ element linear array and the $2 \times 2$ element planar antenna, respectively. It is apparent from fig. 14 and fig. 15 that good input matching is achieved over a wide range of frequencies (more than 20\% relative bandwidth) for both these manufactured antenna prototypes. Also, the measured $\mathrm{S}_{11}$ parameters are in good agreement with the simulated values. For the linear array, the difference in the level of the Sparameters and the little frequency shift can be attributed to variation of the length of the center conductor of the SMA probe, which was cut manually at the lab. In case of the $2 \times 2$ planar array, there are additional peaks in the measured $S_{11}$ parameter. In the simulation, the $2 \times 2$ planar array was excited with a waveguide port at the rectangular waveguide opening. In reality, when the antenna is measured with a waveguide flange, there is an additional transition from rectangular waveguide to SMA probe. This extra transition is assumed to cause the additional peaks in the measured $S_{11}$ parameter of the $2 \times 2$ planar antenna.

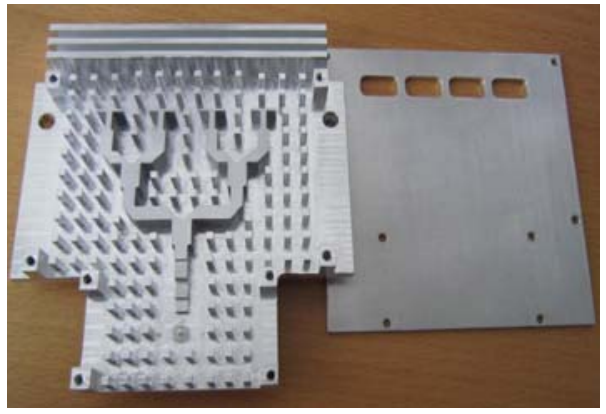

Fig.12 Manufactured prototype of $4 \times 1$ element linear array antenna.

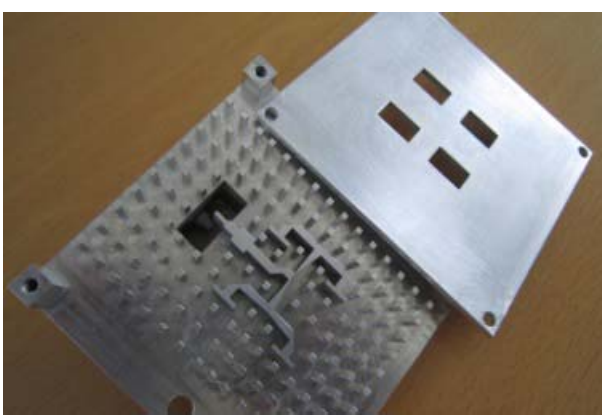

Fig. 13 Manufactured prototype of $2 \times 2$ element planar array antenna.

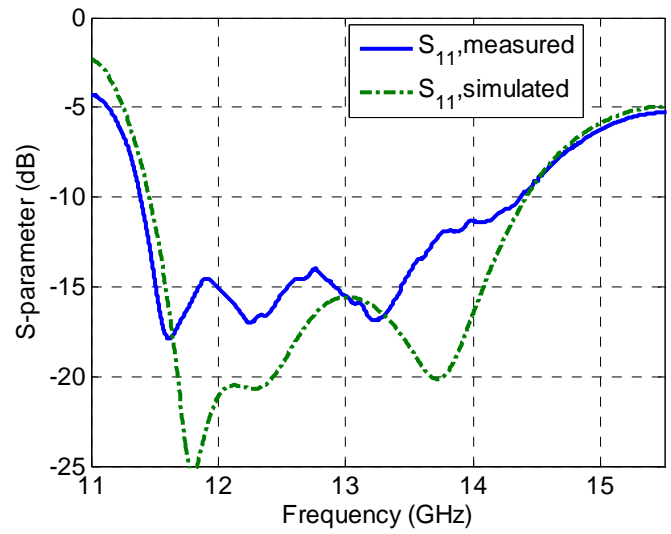

Fig.14 Measured and simulated $S_{11}$ for the $4 \times 1$ element linear array antenna. 


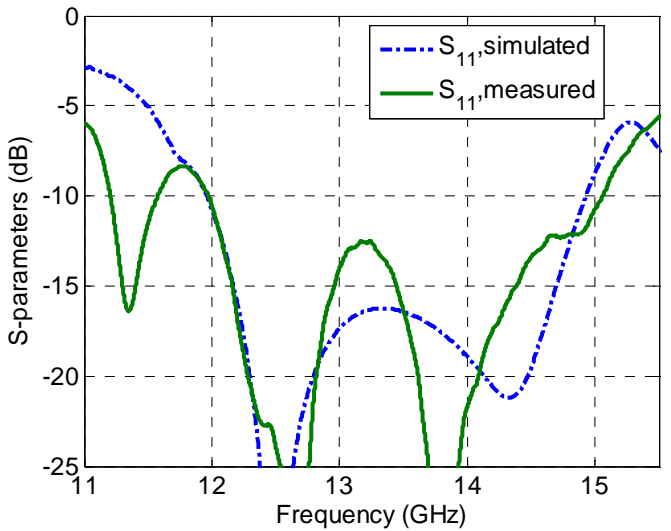

Fig. 15 Measured and simulated $S_{11}$ for the $2 \times 2$ element planar array antenna.

\section{b) Radiation Patterns:}

The radiation characteristics of both these antennas were measured in our own anechoic chamber. The measured radiation patterns are shown in fig.16(a) and fig.16(b) at several frequency points in two principal planes of the linear array. In fig. 17 (a) and fig.17 (b), the measured patterns in the two principal planes of the $2 \times 2$ array are also shown.

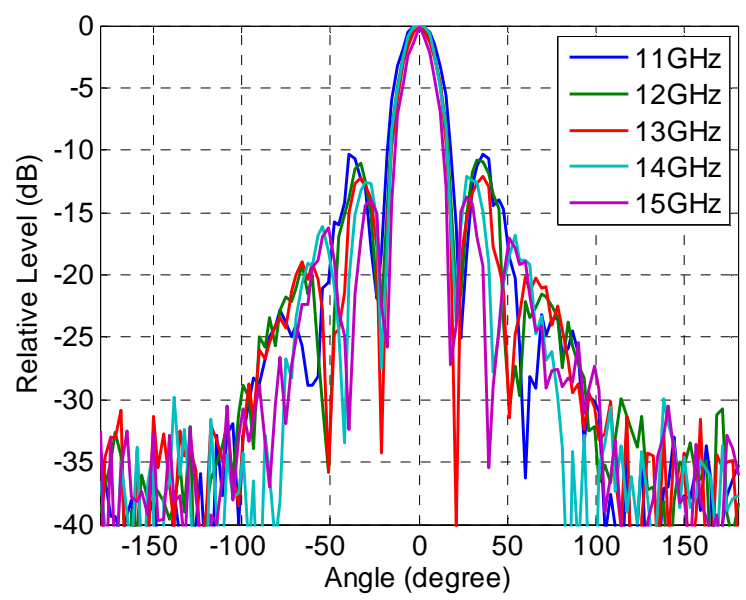

Fig.16 (a) Measured $\mathrm{H}$ plane radiation patterns for the linear array.

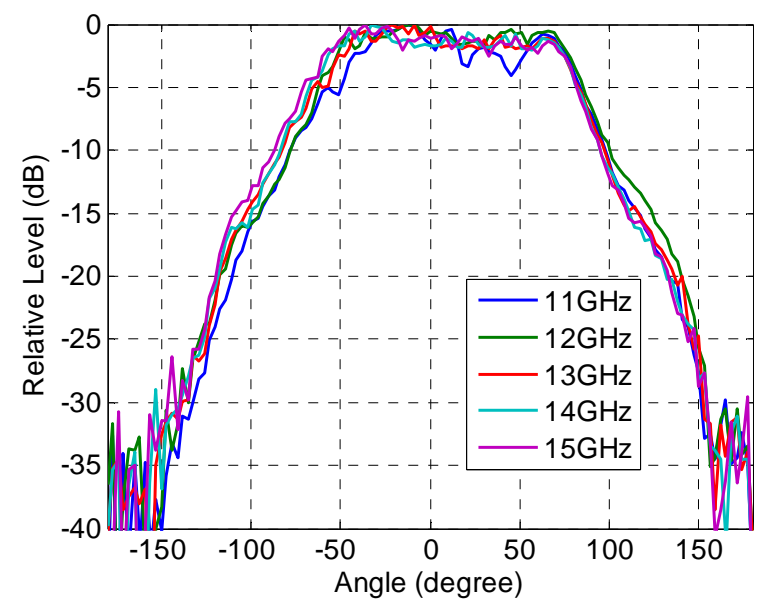

Fig.16 (a) Measured E plane radiation patterns for the linear array.
For the $2 \times 2$ array, the cross-polarization in the E-plane has been measured at two frequency points and presented in fig. 17 (c). As presented in fig.16 and fig.17, the measured and simulated radiation patterns are in quite good agreements for both these two antennas. For the linear array antenna, the first sidelobe level in $\mathrm{H}$-plane is below $-11 \mathrm{~dB}$ over the whole frequency band of interest. For the $2 \times 2$ array, the sidelobe is below $-12.5 \mathrm{~dB}$ in $\mathrm{H}$-plane for all the measured frequency points. In E-plane, the sidelobe levels remain below $-10 \mathrm{~dB}$ at the lower frequencies, but they rise up to a level of $-7.65 \mathrm{~dB}$ at the upper end of the frequency band. These high sidelobes are also present with a level of $-8.35 \mathrm{~dB}$ in simulated patterns. They are caused by the omni-directional pattern of each individual slot in E-plane and the large element spacing (close to $\lambda$ at higher frequency). Also, the array has an extent limited to only two elements in each direction, so we do not have a clear effect of the array factor. For a larger array, this first sidelobe will appear closer to the main lobe and will become lower. For the present array it is combined with the part of the wide grating lobe that appears in real space along the ground plane at $90^{\circ}$ from broadside. The cross-polarization level in Eplane is measured to be $-24 \mathrm{~dB}$, but this level is only related to the accuracy and the misalignments in the measurement chamber.

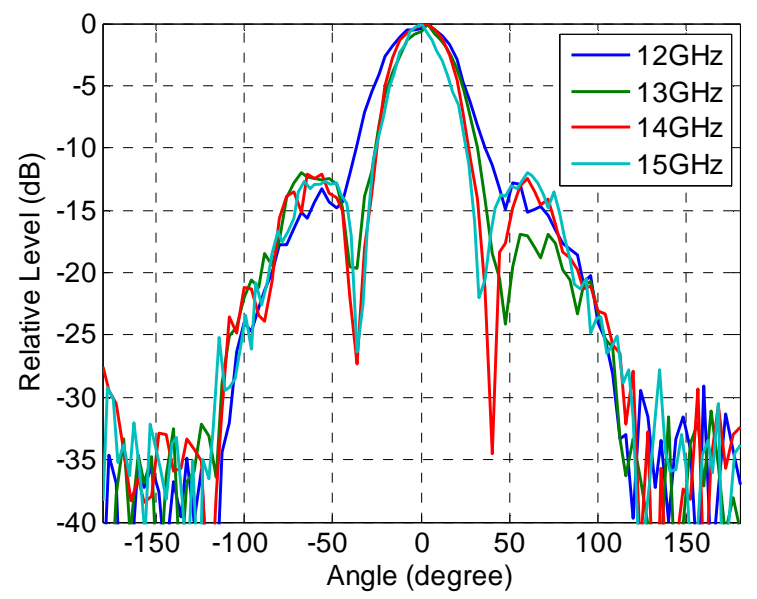

Fig. 17 (a) Measured $\mathrm{H}$ plane radiation patterns for the planar array.

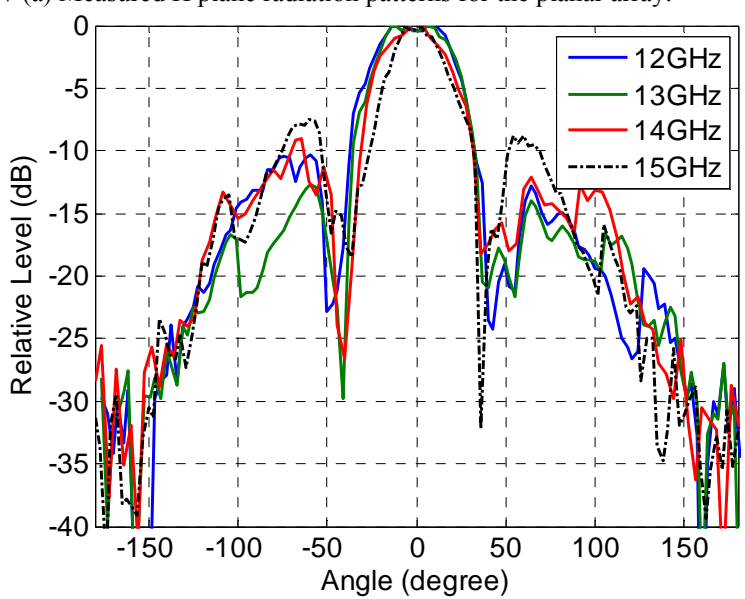

Fig.17 (b) Measured E plane radiation patterns for the planar array. 


\section{c) Measured Gain:}

The realized gain of the $2 \times 2$ element planar array is also measured. The simulated directivity and measured gain versus frequency are shown in fig.18. The dotted lines show the maximum available directivity of an aperture having dimension of $(35 \times 35) \mathrm{mm}^{2}$ (i.e. twice the element spacing in both planes) and when the aperture efficiency is $75 \%$. This is a correct reference aperture of a $2 \times 2$ array [31]. The maximum directivity is calculated by the known formula $4 \pi \mathrm{A} / \lambda^{2}$, valid for big apertures or big arrays. For the present case of $2 \times 2$ element small array, it is difficult to achieve high aperture efficiency. The measured gain is found varying from 12.2 to $13.8 \mathrm{~dB}$ within the frequency range $12-15 \mathrm{GHz}$. The difference between simulated directivity and realized gain is mainly due to the mismatch loss, the losses in feeding network. The ohmic losses in feeding network are found to be less than $0.2 \mathrm{~dB}$ over the entire band of interest.

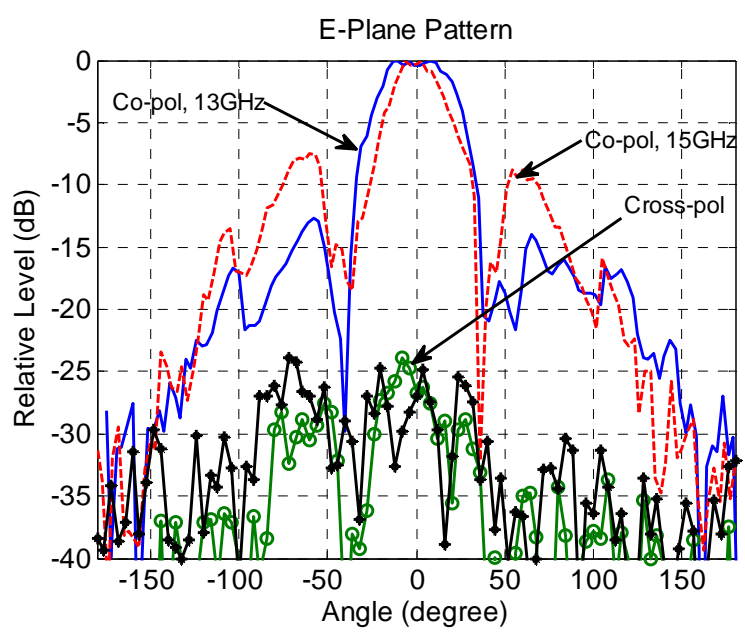

Fig. 17 (c) Measured cross-polarization level for the planar array.

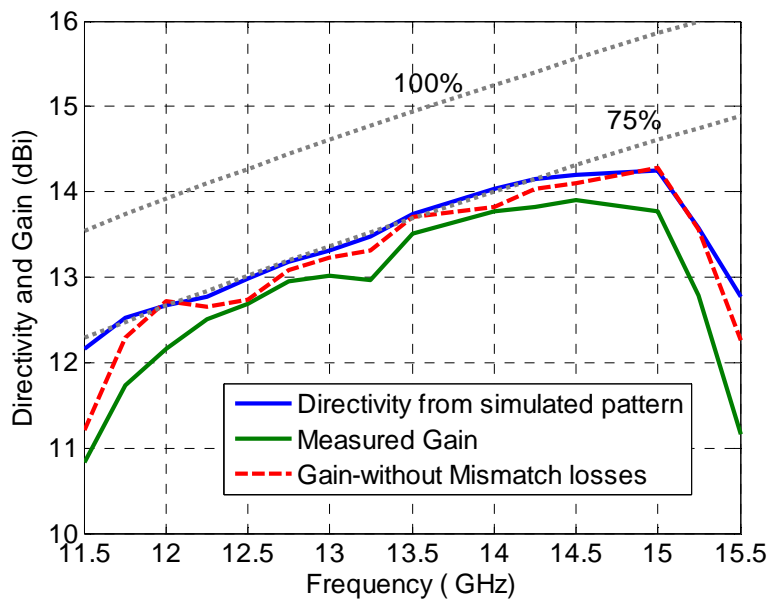

Fig.18 Simulated directivity and measured gain for the planar array.

\section{CONCLUSION}

Novel single-layer corporate-feed networks for slot array antennas based on the planar gap waveguide technology has been proposed in this work. A $4 \times 1$ element linear slot array and $2 \times 2$ element array have been designed, manufactured and measured. The mechanical assemblies of both antennas are very robust and flexible. The mechanical construction has no requirements at all for good electrical contact between the radiating slot layer and the feed network layer. The radiating slot element, the feeding network and the transitions used in both the antennas have been designed to suppress the reflection coefficient and the results show more than $20 \%$ relative bandwidth of the whole arrays. Achieved impedance bandwidth is much larger than for other arrays of similar size described in [12], and [32-33]. The measured and simulated reflection coefficients agree quite well for both antennas. The measured radiation patterns are also in reasonable agreement with the computed patterns. The measured gain for the $2 \times 2$ element planar array is found to be at least $12.2 \mathrm{dBi}$. Thus, the proposed antenna exhibits promising features such as planar geometry, low ohmic losses and wide bandwidth.

The presented $2 \times 2$ slot array element can be used as a subarray to build up much larger antenna. The element spacing of $17.5 \mathrm{~mm}$ corresponds to $0.875 \lambda$, which is small enough to avoid grating lobes. The $2 \times 2$ array occupies only a unit cell area of $35 \times 35 \mathrm{~mm}^{2}$ including the distribution network. This small extent has been possible by compressing the distribution network. Therefore, we have used only one pin row between some parts of the distribution network, instead of the recommended two rows. Still, the distribution network worked. In order to use the $2 \times 2$ array as a sub-array in a large array it must be optimized numerically as a unit cell in an infinite array configuration using periodic boundary conditions, so as to include the effects of mutual coupling between sub-arrays. The feeding network for the full array can be designed by using the same $3 \mathrm{~dB}$ power dividers that we have used here, in a full corporate distribution network connecting all sub-arrays. The present work shows that it should be possible to use ridge gap waveguides to realize high gain, low loss slot arrays consisting of two metal plates, one with a texture of ridges and pins, and the other with an array of slots, and with an air gap between the two plates. However, some parts of the ridge on the textured plate are quite thin which may complicate the manufacturing at higher frequencies.

\section{ACKNOWLEDGMENT}

The authors would like to thank Dr. Ali Khalegi of K.N.Toosi University of Technology, Iran for his help regarding the manufacturing of the antennas.

\section{REFERENCES}

[1] A. Borji, D. Busuioc and S. Safavi-Naeini, "Efficient, Low-Cost Integrated Waveguide-Fed Planar Antenna Array for $\mathrm{Ku}$-Band Applications," IEEE Antennas and Wireless Propag. Letters, vol.8, pp.336-339, 2009.

[2] D M. Pozar, " Considerations for Millimeter Wave Printed Antennas," IEEE Transection on Antennas and Propagation, vol.31, no.5, pp.740747, September 1983. 
[3] E.Levine, G. Malamud, S.Shtrikman and D. Treves, "A study of microstrip array antennas with the feed network," IEEE Transection on Antennas and Propagation, vol.37, no.4, pp.426-464, April 1989.

[4] X. P. Chen, K. Wu, L. Han, and F. H. , "Low-cost high gain planar antenna array for 60-GHz band applications," IEEE Trans. Antennas and Propag., vol. 58, no. 6, pp. 2126-2129, Jun. 2010.

[5] M. Bozzi, A. Georgiadis, and K. Wu, "Review of substrate-integrated waveguide circuits and antennas," Microw., Antennas Propag., IET, vol. 5, no. 8, pp. 909-920, Jun. 2011.

[6] M. Bozzi, M. Pasian, L. Perregrini and K. Wu, "On the losses in Substrate Integrated Waveguides and Cavities," International Journal of Microw. and Wireless Tech. vol. 5, no. 1, pp. 395-401, 2009.

[7] J. Hirokawa and M. Ando, "Efficiency of 76-GHz post-wall waveguidefed parallel-plate slot arrays," IEEE Trans. Antenna Propag., vol.48, no. 11, pp. 1742-1745, Nov. 2000.

[8] YKimura, T.Hirano, J.Hirokawa and M.Ando, "Alternating-phase fed single-layer slotted waveguide arrays with chokes dispensing with narrow wall contacts," IEE Proc.-Microw. Antennas Propag , Vol. 148, No 5, October 2001.

[9] S. Park, Y. Tsunemitsu, J. Hirokawa, and M. Ando, "Center feed single layer slotted waveguide array," IEEE Trans. Antennas and Propag., vol 54, no. 5, pp. 1474-1480, May 2006.

[10] S. Fujii, Y. Tsunemitsu, G. Yoshida, N. Goto, M. Zhang, J. Hirokawa, and M. Ando, "A wideband single-layer slotted waveguide array with an embedded partially corporate feed," in Proc. Int. Symp. Antennas \& Propag., TP-C27-5, Oct. 2008.

[11] T. Tsugawa, Y. Sugio, and Y. Yamada, "Circularly polarized dielectricloaded planar antenna excited by the parallel feeding waveguide network," IEEE Trans. Broadcasting, vol. 43, no. 2, pp. 205-212, June 1997.

[12] Y. Miura, J. Hirokawa, M. Ando, Y. Shibuya, and G. Yoshida, "Doublelayer full-corporate-feed hollow-waveguide slot array antenna in the 60 GHz-band," IEEE Trans. Antennas and Propag., vol. 59, no. 8, pp. 2844-2851, Aug. 2011.

[13] P.-S. Kildal, E. Alfonso, A. Valero-Nogueira, E. Rajo-Iglesias, "Local metamaterial-based waveguides in gaps between parallel metal plates," IEEE Antennas and Wireless Propagation letters, vol. 8, pp. 84-87, 2009

[14] E. Rajo-Iglesias, P.-S. Kildal, "Numerical studies of bandwidth of parallel plate cut-off realized by bed of nails, corrugations and mushroom-type EBG for use in gap waveguides," IET Microwaves, Antennas \& Propagation, vol.5, no.3, pp. 282-289, March 2011.

[15] P.-S. Kildal, "Three metamaterial-based gap waveguides between parallel metal plates for $\mathrm{mm} / \mathrm{submm}$ waves", $3^{\text {rd }}$ European Conference on Antennas and Propagation, Berlin, March 2009.

[16] P.-S. Kildal, A. Uz Zaman, E. Rajo-Iglesias, E. Alfonso and A. ValeroNogueira, "Design and experimental verification of ridge gap waveguides in bed of nails for parallel plate mode suppression," IET Microwaves, Antennas \& Propagation, vol.5, iss.3, pp. 262-270, March 2011.

[17] A. Uz. Zaman, P.-S. Kildal, M. Ferndahl and A. Kishk, "Validation of Ridge Gap Waveguide Performance Using in-house TRL Calibration Kit," 4th European Conference on Antennas and Propagation, Barcelona, April 2010.

[18] A. Valero-Nogueira, J. Domenech, M. Baquero, J. I. Herranz, E. Alfonso, and A. Vila, "Gap waveguides using a suspended strip on a bed of nails," IEEE Antennas and Wireless Propag. Letters, vol.10, pp. 1006-1009, 2011

[19] Ahmed Kishk and P.-S. Kildal, "Quasi-TEM H-plane Horns with Wideband Open Hard Side-Walls," 4th European Conference on Antennas and Propagation, 2010, Barcelona, Spain, April 12-16, 2010.

[20] A. Valero- Nogueira, E. Alfonso, J.I. Herranz and M. Baquero, " Planar slot array antenna fed by oversized Quasi TEM waveguide," Microwave and Optical Technology Letters, vol. 49, no. 8, pp.1875-1877, 2007.

[21] A Uz Zaman and P.-S. Kildal, "Slot Antenna in Ridge Gap Waveguide Technology," 6th European Conference on Antennas and Propagation, Prague, March, 2012.

[22] H. Kirino and K. Ogawa, “A 76 GHz Multi-Layered Phased Array Antenna Using a Non-Metal Contact Metamaterial Waveguide," IEEE Transactions on Antennas and Propag., vol. 60, no. 2, pp. 840-853, February 2012.
[23] E. Pucci, E. Rajo-Iglesias, J.-L. Vasquuez-Roy and P.-S. Kildal, "Planar Dual-Mode Horn Array with Corporate-Feed Network in Inverted Microstrip Gap Waveguide", submitted to IEEE Transactions on Antennas and Propagation, July 2013.

[24] S. Martinez Giner, A. Valero-Nogueira,J. I. H. Gerruzo and M. Baquero, "Excitation of Untitled Narrow wall slot in Groove gap waveguide by using a Parasitic dipole ," 7th European Conference on Antennas and Propagation, Gothenburg, April, 2013.

[25] H. Raza, J. Yang, P.-S. Kildal and E. Alfonso, "Resemblance between Gap Waveguides and Hollow Waveguides," Accepted for IET Microwaves, Antennas \& Propagation.

[26] M. Bosiljevac, Z. Sipus, P.-S. Kildal, "Construction of Green's functions of parallel plates with periodic texture with application to gap waveguides - A plane wave spectral domain approach", IET Microw. Antennas Propag., Vol. 4, Iss. 11, pp. 1799-1810, Nov. 2010.

[27] A. Polemi, S. Maci, P.-S. Kildal, "Dispersion characteristics of metamaterial-based parallel-plate ridge gap waveguide realized by bed of nails", IEEE Transactions on Antennas and Propagation, Vol. 59, No 3, pp. 904-913, March 2011.

[28] J. Uher, J. Bornemann and U. Rosenburg, "Waveguide Components for Antenna Feed Systems: Theory and Cad", Artech House,Inc, ISBN 089006-582-9, 1993

[29] Y. C. Leong and S. Weinreb, "Full band waveguide-to-microstrip probe transitions," in 1999 IEEE Microwave Theory Tech. Symp. Dig. , June 1999, pp. $1435-1438$.

[30] A. Uz Zaman and P.-S. Kildal, "Ku-Band Linear Slot-Array in Ridge Gapwaveguide Technology," 7th European Conference on Antennas and Propagation, Gothenburg, April, 2013.

[31] P.-S. Kildal, "Fundamental Directivity and Efficiency Limitations of Single and Multi-port Antennas," 2nd European Conference on Antennas and Propagation, Edinburg, November 2007.

[32] Y. Zhang, Z. N. Chen, X. Qing and W. Hong, "Wideband Millimeterwave Substrate Integrated Waveguide Slotted Narrow-wall Fed Cavity Antennas," IEEE Trans. Antennas and Propag., vol. 59, no. 5, pp. 1488-1496, May 2011.

[33] M. H. Waida and A. E. Fathy, "Substrate Integrated Waveguide Ku-band Cavity Backed $2 \times 2$ Microstrip Patch Array Antenna," IEEE Antennas and Wireless Propag. Letters, vol.8, pp. 1054-1056, 2009.

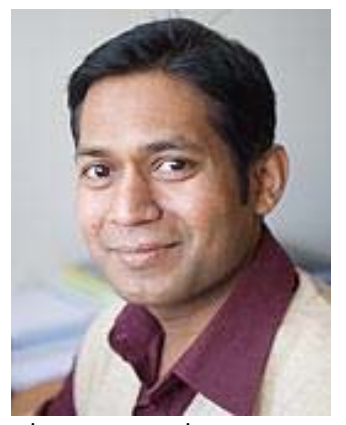

Ashraf Uz Zaman was born in Chittagong, Bangladesh. He received his BSc. in Electrical and Electronics Engineering from Chittagong University of Engineering and Technology, Bangladesh. In 2007, he received his MSc. degree from Chalmers University of Technology, Sweden. At present, he is with the Communication, Information Theory and Antenna division of same university and is working towards his $\mathrm{PhD}$. His main research interest includes millimeter and sub millimeter waveguide technology, frequency selective surfaces, microwave passive components, packaging techniques, integration of MMIC with the antennas etc.

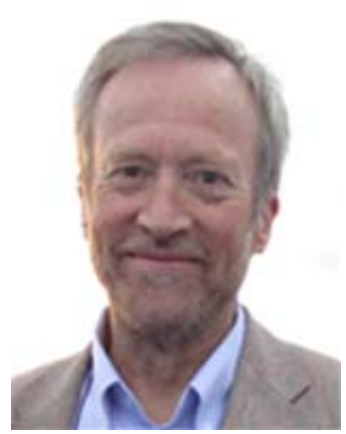

Per-Simon Kildal (M'76-SM'81-F'95) is professor in antennas at Chalmers University of Technology in Gothenburg, Sweden since 1989. He is heading the Antenna group. His main tasks are to lead and supervise research and education within antenna systems. Until now, 18 graduate students have received a $\mathrm{Ph}$.D. from him. Kildal received himself two doctoral degrees from the Norwegian Institute of Technology in Trondheim. Kildal has authored more than 120 articles in scientific journals; concerning antenna theory, analysis, design and measurements, two of which was awarded best paper awards by IEEE (1985 R.W.P. King Award and 1991 Schelkunoff Prize Paper 
Award). In 2011 he received the prestigious Distinguished Achievements Award from the IEEE Antennas and Propagation Society. Kildal has done the electrical design of the $40 \mathrm{~m} \times 120 \mathrm{~m}$ cylindrical reflector antenna and line feed of the EISCAT scientific organization, and the dual-reflector Gregorian feed of the $300 \mathrm{~m}$ radio telescope in Arecibo. He is the inventor behind technologies such as dipole with beam forming ring, the hat antenna, and the eleven feed. Kildal was the first to introduce the reverberation chamber as an accurate measurement instrument tool for Over-The-Air (OTA) characterization of small antennas and wireless terminals for use in multipath environments with fading. Kildal is also the originator of the concept of soft and hard surfaces from 1988, today being regarded as the first metamaterials concept. This concept is the basis of his latest and most fundamental invention, the gap waveguide technology. His research is innovative and industrially oriented, and has resulted in several patents and related spinoff companies, the most known being Bluetest $\mathrm{AB}$, see www.kildal.se for more details. Kildal organizes and lectures in courses within the European School of Antenna (ESoA, www.antennasvce.org). His textbook Foundations of Antennas - A Unified Approach (Lund, Sweden: Studentlitteratur, 2000) was well received, and is now in the process of being revised. 